\title{
Клинический опыт периоперационного применения декаметоксина без введения антибиотиков
}

\author{
А. Ю. Глаголева, М. Ю. Крестянов, В. М. Лысенко, Д. С. Завертиленко, С. И. Саволюк
}

Национальная академия последипломного образования имени П. Л. Шупика, г. Киев

\section{Clinical experience of perioperative application of decamethoxin without application of antibiotics}

\author{
A. Yu. Glagolieva, M. Yu. Krestianov, V. M. Lysenko, D. S. Zavertylenko, S. I. Savoliuk \\ Shupyk National Medical Academy of Postgraduate Education, Kyiv
}

\section{Реферат}

Цель. Оценить эффективность и безопасность использования раствора декаметоксина с целью противомикробной профилактики в плановой хирургии.

Материалы и методы. В работе представлены результаты клинического наблюдения 68 пациентов, которым были выполнены открытые и лапароскопические операции на органах брюшной полости и малого таза без профилактического введения антибиотиков, но с использованием декаметоксина для обработки операционного поля, ран и орошения брюшной полости.

Результаты. Среди пациентов, оперированных с применением исключительно антисептика Декасана® в качестве противомикробной профилактики, не выявлено инфицирования области хирургического вмешательства (ИОХВ). Ни у одного пациента не развился лимфангит или регионарный лимфаденит. Ни у одного больного не зафиксировали проявлений системной воспалительной реакции.

Выводы. Нерациональная антибиотикопрофилактика при чистых хирургических вмешательствах в настоящее время приводит к развитию антибиотикорезистентности микроорганизмов, аллергизации пациентов и в целом является экономически неоправданной. У оперированных пациентов не наблюдали ИОХВ и прочих инфекционных осложнений, что позволяет рассматривать декаметоксин как перспективный препарат антимикробной профилактики в чистой хирургии.

Ключевые слова: антибиотикопрофилактика; антибиотикорезистентность; плановая хирургия; антисептики.

\section{Abstract}

Objective. To estimate efficacy and safety of the decamethoxin solution application for antimicrobial prophylaxis in elective surgery.

Materials and methods. There were presented the results of clinical observation of 68 patients, to whom open and laparoscopic operations were performed on abdominal and a small pelvis cavity organs without antibioticoprophylaxis, but with decamethoxin application for the operative field, the wounds and the abdominal cavity irrigation treatment.

Results. Among the patients, operated using solely antiseptic Decasan ${ }^{\circledR}$ for antimicrobial prophylaxis, the infectioning of the surgical intervention region (ISI) was not revealed. In no one patient lymphangitis or regional lymphadenitis have been developed. In no one patient the signs of systemic inflammatory reaction have been revealed.

Conclusion. Nonrational antibioticoprophylaxis in clean surgical interventions leads to antibioticoresistence of microorganisms, allergization of patients and in general is economically unjustified. In the patients operated the ISI and other infectious complications were not revealed, permitting to consider decamethoxin as a perspective antimicrobial preparation for antimicrobial prophylaxis in clean surgery.

Keywords: antibioticoprophylaxis; antibioticoresistence; elective surgery; antiseptics.

Развитие антибиотикорезистентности представляет собой глобальную проблему как с точки зрения опасности утраты контроля над инфекционным процессом у пациентов, так и в связи с увеличением финансовой нагрузки на систему здравоохранения, вынужденную производить новые типы антибактериальных препаратов [1]. Первооткрыватель пенициллина Александр Флеминг в своем интервью после получения Нобелевской премии в 1945 г. предупреждал, что если ненадлежаще использовать антибиотики в дозах, сублетальных для микроорганизмов, то последние станут к ним нечувствительны. Хотя Флемингу и не были известны основные механизмы антибиотикорезистентности микроорганизмов, такие как горизонтальный перенос генов, гетеро- и колонизационная ре- зистентность, клональная интерференция и прочие, ученый все же уделял много внимания исследованию топических противомикробных средств (антисептиков) как альтернативы системному введению антибиотиков при определенных показаниях. Также Флеминг предположил, что антисептики могут оказывать положительный эффект при лечении инфицированных ран с минимальной токсичностью для организма человека [2].

Антисептические свойства некоторых химических веществ, например сульфаниламидов, были известны еще за несколько десятилетий до открытия Флемингом явления «антибиоза», а их клиническое применение по ограниченным показаниям актуально и в настоящее время (к примеру, бисептола). 
Сегодня роль антисептиков и перспективы их более широкого применения активно пересматриваются, а результаты проводимых исследований вскоре позволят внести эти препараты в программы рациональной противомикробной профилактики.

В целом антисептики делят на две категории - неорганического и органического происхождения. Среди антисептиков органического происхождения наиболее эффективными признаны спирты (этанол, метанол), альдегиды (формальдегид), фенолы, четвертичные соединения аммония (декаметоксин) и гуанидины [3]. Из неорганических антисептиков пользуются достаточно широкой популярностью препараты йода (раствор кристаллического йода, повидон-йод), хлора (хлоргексидин), бора (борная кислота) и фтора, а также некоторые окислители (перекись водорода). Следует отметить, что практически ни одно из указанных веществ не вызывает клинически значимой противомикробной резистентности при длительном применении или использовании в высоких дозах. Напротив, лимитирующим фактором в их использовании является способ создания достаточной бактерицидной концентрации в очаге инфекции. Исключение составляет хлоргексидин, использование которого несет в себе риск индукции резистентности к антибиотикам резерва и ассоциировано с высокой вероятностью развития серьезных аллергических реакций [4].

В зависимости от физико-химических свойств разные антисептики следует применять в правильных концентрациях при наличии соответствующих показаний, так как упомянутые выше препараты имеют различные спектры противомикробного действия, сила которого может изменяться при различном типе раневого биоценоза и отделяемого.

В систематическом обзоре и мета-анализе Q. J. Tong и соавторы сравнивали эффективность использования топических антибиотиков и антисептиков для профилактики раневой инфекции в хирургии [5]. Было обнаружено, что статистически значимой разницы в эффективности снижения абсолютного риска инфицирования раны между указанными группами препаратов не было $(p=0,09)$.

Известно, что в 30 - 50\% наблюдений антибиотики в лечебных учреждениях вводят пациентам с профилактической целью, и это нецелесообразно также и с экономической точки зрения [6].

Противомикробная профилактика при «чистых» операциях направлена на сокращение количества микроорганизмов в операционном поле до такового, с которым успешно может справиться иммунная система пациента. Эта профилактика заключается в препятствовании связыванию бактерий с компонентами клеток организма хозяина и в уменьшении объема бактериальной колонизации места интервенции [7]. В частности, декаметоксин в концентрации 3,8 мкг/мл обладает способностью уменьшать количество адгезированных бактериальных клеток стафилококков на 58,46 - 59,60\%, а в концентрации 15,2 мкг/мл - на 26,48 - 26,51\% количество эшерихий [8].

Механизм антимикробного действия декаметоксина основан на том, что препарат, концентрируясь на цитоплазматической мембране (ЦПМ) клетки микроорга- низма и соединяясь с фосфатидными группами липидов ЦПМ, нарушает ее проницаемость. В отношении стафилококков, стрептококков, дифтерийной и синегнойной палочек декаметоксин проявляет выраженное бактерицидное действие, имеет фунгицидный эффект против многих видов грибов (аспергиллы, дрожжевые грибы), а также обладает противоцистоидным (трихомонады, лямблии) и вирусоцидным действием. Декаметоксин высокоактивен относительно микроорганизмов, стойких к антибиотикам - пенициллину, левомицетину, тетрациклинам, стрептомицину и др.).

Всасываемость декаметоксина неповрежденной кожей и раневой поверхностью очень низкая и вероятность передозировки крайне маловероятна. При совместном применении декаметоксина и антибактериальных препаратов в процессе лечения повышается чувствительность антибиотикорезистентных микроорганизмов к антибиотикам. Следует отметить, что стойкие к декаметоксину формы даже при его длительном применении образуются медленно и не превышают эффективных концентраций препарата.

Цель исследования: изучение клинической эффективности и переносимости препарата Декасана® (на основе декаметоксина), используемого для обработки операционного поля, а также орошения брюшной полости и раны перед наложением швов без системной антибиотикопрофилактики при ряде плановых абдоминальных вмешательств [9].

\section{Материалы и методы исследования}

Согласно действующему приказу Министерства зравоохранения Украины №181 от 04.04.2008 г., необходимо всегда парентерально вводить антибиотик с целью профилактики за 30 - 60 мин до выполнения хирургического разреза и прекращать его введение сразу после операции (категория IA). Также указывается, что антимикробная профилактика рекомендуется при операциях, которые ассоциируются с высоким риском развития инфекции, и при операциях, развитие инфекции при которых приводит к тяжелым или угрожающим жизни осложнениям (сердечно-сосудистые, ортопедические операции с имплантацией различных устройств). Учитывая современные данные мировой литературы касательно эффективности антисептиков, в нашей клинике ряду пациентов с низким риском развития инфекции места хирургического вмешательства мы предложили выполнить операцию без антибиотикопрофилактики, но с применением антисептика Декасана®, на что было получено их письменное согласие. Индивидуальная непереносимость препарата у этих пациентов была исключена. За период с ноября 2017 по май 2018 г. 68 пациентам выполнили плановые оперативные вмешательства: 24 (35,3\%) - паховую герниопластику, из них 14 - открытую по Лихтенштейну, 10 - лапароскопическую преперитонеальную аллогерниопластику (ТАРР); 4 (5,9\%) - лапароскопическую крурорафию с фундопликацией по Ниссену по поводу диафрагмальной грыжи; 11 (16,2\%) - лапароскопическую холецистэктомию; 15 (22\%) - лапароскопическую кистэктомию яичника; 14 (20,6\%) - гистерэктомию при фиброматозе мат- 
ки, из них 8 - лапароскопическую, 6 - открытую абдоминальную. Статистически значимых различий по полу, возрасту, антропометрическим данным (индекс массы тела), соматическому статусу, структуре и степени выраженности сопутствующей патологии у больных не было.

Декасаном® обрабатывали операционное поле, 200 мл препарата орошали брюшную полость через ирригатор при лапароскопических вмешательствах или шприцом при открытых операциях (при герниопластике обрабатывали рану перед имплантацией сетки), 20 - 25 мл использовали для промывания троакарных или лапаротомных ран перед их ушиванием.

При выявлении сахарного диабета, независимо от степени компенсации, а также иммунодефицитных состояний до операции, принимая во внимание повышенный риск развития раневой инфекции, применяли стандартную схему антибиотикопрофилактики и данных пациентов в исследование не включали.

\section{Результаты}

В упомянутом приказе Министерства здравоохранения Украины ИОХВ обозначена гнойно-воспалительная инфекция, которая возникла в течение 30 сут после операции без установки имплантата, трансплантата и протезного устройства или в течение 1 года с установкой имплантата, трансплантата и протезного устройства.

Среди пациентов, оперированных нами с применением исключительно антисептика Декасана® в качестве противомикробной профилактики, не было выявлено ни одного случая ИОХВ: не наблюдали патологического отделяемого из ран, отечности или гиперемии краев, повышенной болезненности в области послеоперационной раны. Ни у одного пациента не развился лимфангит или регионарный лимфаденит. По данным клинико-лабораторных исследований также ни у одного больного не зафиксировали проявлений системной воспалительной реакции. Температура тела, не превышающая $37,1^{\circ} \mathrm{C}$, отмечена только у 6 пациенток на 1 -е сутки после открытой гистерэктомии. После внутривенного применения парацетамола температура тела нормализовалась. У пациентов, которым выполнили герниопластику, проявлений инфицирования сетчатых имплантатов не было ни после открытых, ни после лапароскопических вмешательств. После крурорафии с фундопликацией по Ниссену признаки медиастинита не диагностировали ни у одного пациента.

\section{Обсуждение}

По данным Национальной сети безопасности здравоохранения, полученным при анализе результатов из Центров по контролю и профилактике заболеваний США, доля хирургической инфекции (ХИ) среди всех внутрибольничных инфекций составляет 17\%. Из 100000 наблюдений внутрибольничных инфекций, зарегистрированных в течение одного года, в 8000 ХИ явилась причиной смерти пациентов. Частота ХИ после операций сильно варьирует в зависимости от типа интервенции и основных факторов риска со стороны пациента, однако средний показатель по США составляет от 2 до 3\%. При разви- тии ХИ длительность пребывания пациентов в стационаре и связанные с этим расходы существенно возрастают [10]. Таким образом, адекватная профилактика инфекционных осложнений при хирургических вмешательствах имеет первостепенное значение.

Инфицирование области «чистого» хирургического вмешательства развивается в 0,5 - 6\% наблюдений [11]. Предоперационная обработка кожи надлежащим антисептиком достоверно уменьшает бактериальную колонизацию области интервенции и предотвращает развитие раневой инфекции в дальнейшем [12].

В 1964 г. Национальный исследовательский совет США предложил классификацию хирургических ран для прогнозирования риска ХИ. Современная модифицированная классификация, разработанная для оценки возможных осложнений в виде ХИ в периоперационном периоде, включает четыре класса ран [13].

Чистые - плановые операции; первично ушитая рана без травмы и признаков инфекции или воспаления раны; операции с сохранением целостности пищеварительного канала, мочевыводящего канала и половых органов, дыхательных путей, полости рта и глотки, если соблюдена техника асептики (риск ХИ меньше 2\%).

Чисто-контаминированные - вмешательства со вскрытием просвета мочевыводящих, дыхательных путей или пищеварительного канала без явного загрязнения полостей тела их содержимым; операции на желчевыводящих путях без признаков инфекции; процедуры, связанные с доступом через слизистую оболочку ротоглотки; чистые неотложные операции; повторные операции в течение 7 дней после первичной чистой интервенции; тупая травма (риск ХИ меньше 10\%).

Контаминированные - открытая рана после травмы; операции с нарушением техники асептики; наличие очага воспаления за пределами места интервенции; проникающая травма до 4 ч после нанесения; хроническая рана, для которой можно применить трансплантацию кожи (риск ХИ 20\%).

Грязные - проникающие ранения более чем через 4 ч после нанесения; наличие мертвых тканей в ране; признаки инфекции в месте вмешательства; нехирургическая перфорация органов пищеварительного канала, желчевыводящих или дыхательных путей (риск ХИ 40\%).

Целесообразность рутинной антибиотикопрофилактики при плановых операциях по поводу паховой грыжи с использованием сетчатого имплантата остается спорной. Частота раневой инфекции после герниопластики по данным международной литературы составляет от 0 до 14\% [14]. При этом результаты большинства двойных слепых рандомизированных контролируемых исследований не подтверждают, что использование антибиотикопрофилактики достоверно снижает частоту ХИ [15 - 17].

Об уровне ХИ судят по так называемым индексам риска, которые определяют, применяя наиболее известные системы SENIC (Study of the Efficacy of Nosocomial Infection Control - Изучение эффективности нозокомиального инфекционного контроля) и NNIS (National Nosocomial Infectiona Surveillance System - Национальная система наблюдения за нозокомиальными инфекциями США). Со- 
гласно SENIC наиболее важными факторами риска являются: операция на брюшной полости; длительность операции более 2 ч; контаминированная рана; более трех клинических диагнозов у пациента. Отсутствие факторов риска имеет предиктивное значение в 1\% относительно ХИ, а наличие 1, 2, 3 и 4 факторов - 3,6, 8,9, 17,2 и 27,0\% соответственно [18]. Оценка, полученная по системе NNIS, несколько субъективна, и сама NNIS имеет определенные ограничения, поскольку в качестве одного из критериев использует показатель анестезиологического риска по классификации ASA (American Society of Anesthesiologist - Американского общества анестезиологов).

В руководствах Европейского герниологического общества (ЕГО) при открытых паховых герниопластиках не рекомендуется применять антибиотикопрофилактику у пациентов с низким риском развития инфекционных осложнений ввиду отсутствия данных о том, что это достоверно препятствует инфицированию сетчатого импланта и развитию раневой инфекции [19]. Однако экспертная группа ЕГО все же рассматривает необходимость превентивного применения антибиотиков при наличии факторов риска, связанных с пациентом (рецидивная грыжа, преклонный возраст, иммуносупрессия) или же с самой процедурой (длительность операции, необходимость в установке дренажа и т. п.).

При плановой лапароскопической холецистэктомии риск инфекционных осложнений очень низок и составляет 0,4 - 1,1\%. Согласно результатам проспективных рандомизированных исследований M.A.T. Passos и соавторов и S. Ruangsin и соавторов антибиотикопрофилактика при указанной операции не приводит к снижению уровня раневой инфекции и, следовательно, ее можно не проводить [20, 21].

Что касается плановых гистерэктомий (как абдоминальных, так и вагинальных), то у пациентов, которым проводили антибиотикопрофилактику, частота послеоперационных инфекций и тазовых инфекционных осложнений была меньше, а также реже возникала гипертермия по сравнению с пациентами, которых оперировали без противомикробной профилактики. Эти данные приведены в Кокрейн обзоре [22]. Однако рандомизированных исследований, в которых бы сравнивались результаты превентивного применения антибиотиков и антисептиков при плановых гистерэктомиях, не проводили. В нашей практике после указанных вмешательств с применением декаметоксина для обработки операционного поля и лаважа ран без антибиотикопрофилактики инфекционных осложнений не было.

\section{Выводы}

1. Установить универсальные объективные факторы риска развития инфекции и их значимость при чистых хирургических операциях крайне сложно, соответственно четко сформулировать обоснованные показания к антибиотикопрофилактике затруднительно, поэтому необходим поиск иных способов предупреждения инфицирования послеоперационных ран.

2. Полученные данные дают основание сделать заключение, что применение раствора декаметоксина эффективно препятствует развитию раневой инфекции при ря- де чистых плановых открытых и лапароскопических хирургических вмешательств. Наряду с отмеченным противомикробным профилактическим действием, ни в одном наблюдении не было зарегистрировано нежелательных побочных эффектов применения декаметоксина в виде местной или общей аллергической реакции либо перекрестной реакции с местными анестетиками. Таким образом, превентивный противомикробный эффект декаметоксина можно считать сравнимым с таковым антибиотиков, что позволяет избегать применения последних при плановых абдоминальных хирургических вмешательствах.

3. Применяя декаметоксин, можно рационализировать использование антибиотиков в хирургии, сделав его экономически и клинически эффективным, что обеспечит снижение частоты нежелательных антибиотикоассоциированных явлений (дисбактериоза, аллергизации), а также риска развития антибиотикорезистентности.

\section{References}

1. Edmiston CE Jr, Leaper D, Spencer M, Truitt K, Litz Fauerbach L, Graham $\mathrm{D}$, et al. Considering a new domain for antimicrobial stewardship: Topical antibiotics in the open surgical wound. Am J Infect Control. 2017 Nov 1;45(11):1259-66. doi: 10.1016/j.ajic.2017.04.012.

2. Roberts CD, Leaper DJ, Assadian O. The Role of Topical Antiseptic Agents Within Antimicrobial Stewardship Strategies for Prevention and Treatment of Surgical Site and Chronic Open Wound Infection. Advances in Wound Care. 2017;6(2):63-71. doi:10.1089/wound.2016.0701.

3. Assadian O. Octenidine dihydrochloride: chemical characteristics and antimicrobial properties. J Wound Care. 2016 Mar;25(3 Suppl):S3-6. doi: 10.12968/jowc.2016.25.Sup3.S3.

4. Mischenko N. Hlorgeksidin: novyie dannyie trebuyut bolee ostorozhnogo primeneniya. HIrurgIya, ortopedIya, travmatologIya. 2017;2(28): 22. [In Russian].

5. Tong QJ, Hammer KD, Johnson EM, Zegarra M, Goto M, Lo TS. A systematic review and meta-analysis on the use of prophylactic topical antibiotics for the prevention of uncomplicated wound infections. Infect Drug Resist. 2018 Mar 16;11:417-25. doi: 10.2147/IDR.S151293.

6. Ross F, Jones N, Townend A, Bhaskar P. The cost of inappropriate antibiotic prophylaxis in inguinal hernia repair surgery. Int J Surg. 2015;23 (Suppl 1):72-3. doi: 10.1016/j.ijsu.2015.07.320.

7. Terzi C. Antimicrobial prophylaxis in clean surgery with special focus on inguinal hernia repair with mesh. J Hosp Infect. 2006 Apr;62(4):42736. doi: 10.1016/j.jhin.2005.09.017.

8. Gonchar OO, Nazarchuk AA, Paliy DV, Kovalenko IV, Yatsula OV, Burkot VM. Issledovanie deystviya dekametoksina i ego lekarstvennyih form na adgeziyu bakteriy. 2015;4(54):109-12. [In Russian].

9. "InstruktsIya dlya medichnogo zastosuvannya preparatu Dekasan $\mathbb{B}$ " zatverdzhena nakazom MOZ Ukrayini 22.12.2016 \#1391, reestratsiyne posvidchennya \# UA/5364/01/01.

10. E. Patchen Dellinger, Surgical Site Infections, In Netter's Infectious Diseases, edited by Elaine C. Jong and Dennis L. Stevens, Philadelphia, 2012, Pages 295-298, doi.org/10.1016/B978-1-4377-0126-5.00052-5.

11. Dumville JC, McFarlane E, Edwards P, Lipp A, Holmes A. Preoperative skin antiseptics for preventing surgical wound infections after clean surgery. Cochrane Database Syst Rev. 2013 Mar 28;(3):CD003949. doi: 10.1002/14651858.CD003949.pub3.

12. Kamel C, McGahan L, Polisena J, Mierzwinski-Urban M, Embil JM. Preoperative skin antiseptic preparations for preventing surgical site infections: a systematic review. Infect Control Hosp Epidemiol. 2012 Jun;33(6):608-17. doi: 10.1086/665723.

13. Hryniewicz W, Kulig J, Ozorowski T, Kulig P, Wąchol D. Stosowanie antybiotyków w profilaktyce okołooperacyjnej. Narodowy Instytut Leków, Warsaw. 2011; 1-27.

14. Mazaki T, Mado, K, Masuda H, Shiono M, Tochikura N, Kaburagi $\mathrm{M}$. A randomized trial of antibiotic prophylaxis for the prevention of surgical site infection after open mesh-plug hernia repair. Am J Surg. 2014;207:476-84. 
15. Aufenacker TJ, van Geldere D, van Mesdag T, Bossers AN, Dekker $\mathrm{B}$, Scheijde E, et al. The role of antibiotic prophylaxis in prevention of wound infection ater Lichtenstein open mesh hernia repair o primary inguinal hernia. A multicenter double-blind randomized controlled trial. Ann Surg. 2004;240:955-61.

16. Jain SK, Jayant M, Norbu C. The role of antibiotic prophylaxis in mesh repair of primary inguinal hernias using prolene hernia system: a randomized prospective double-blind control trial. Trop Doct 2008; 38: 80-2.

17. Othman I. Prospective randomized evaluation of prophylactic antibiotic usage in patients undergoing tension free inguinal hernioplasty. Hernia 2011;15:309-13.

18. Ortega G, Rhee DS, Papandria DJ, Yang J, Ibrahim AM, Shore AD, et al. An evaluation of surgical site infections by wound classification system using the ACS-NSQIP. J Surg Res. 2012 May 1;174(1):33-8. doi: 10.1016/j.jss.2011.05.056
19. Zamkowski MT, Makarewicz W, Ropel J, Bobowicz M, Kąkol M, Śmietański M. Antibiotic prophylaxis in open inguinal hernia repair: a literature review and summary of current knowledge. Wideochir Inne Tech Maloinwazyjne. 2016;11(3):127-36.

20. Passos MAT, Portari-Filho PE. Antibiotic prophylaxis in laparoscopic cholecistectomy: is it worth doing? Arquivos Brasileiros de Cirurgia Digestiva : ABCD. 2016;29(3):170-172. doi:10.1590/01026720201600030010

21. Ruangsin S, Laohawiriyakamol S, Sunpaweravong S, Mahattanobon S.The efficacy of cefazolin in reducing surgical site infection in laparoscopic cholecystectomy: a prospective randomized double-blind controlled trial. Surg Endosc. 2015 Apr;29(4):874-81. doi: 10.1007/ s00464-014-3745-X.

22. Ayeleke RO, Mourad S, Marjoribanks J, Calis KA, Jordan V. Antibiotic prophylaxis for elective hysterectomy. Cochrane Database Syst Rev. 2017 Jun 18;6:CD004637. doi: 10.1002/14651858.CD004637. 